\title{
Vorwort zur fünften Auflage.
}

Für die fünfte Auflage habe ich den ganzen Inhalt des Buches wieder einmal überarbeitet, insbesondere den Abschnitt über das NERNST sche Wärmetheorem, welches inzwischen, und zwar in seiner am weitesten gehenden Fassung, überall ausnahmslos Bestätigung gefunden hat und somit jetzt wohl in den sicheren Besitzstand der Theorie übergegangen ist. Seine atomistische Bedeutung, welche in den engen Beziehungen zur Quantenhypothese ihren Ausdruck findet, kann freilich im Rahmen des vorliegenden Werkes selbstverständlich nicht gewürdigt werden.

Berlin, im März 1917.

\section{Vorwort zur sechsten und siebenten Auflage.}

Unter den Ergänzungen, welche die neue Auflage erfahren hat, erwähne ich hier die von J. Сн. Gноsн (Calcutta) aufgestellte Theorie für die Gefrierpunktsdepression starker Elektrolyte, welche die durch lange Zeit hindurch rätselhaft gebliebenen Abweichungen vom OsTwaLd schen Verdünnungsgesetz endgültig aufzuklären scheint (§ 273), sowie die DEBYEsche Zustandsgleichung fester Körper, welche sowohl die Temperaturabhängigkeit der spezifischen Wärme als auch den GRÜNEISENschen Satz für den thermischen Ausdehnungskoeffizienten in sich enthält (§ 285).

Berlin-Grunewald, im Februar 1921 und im Juli 1922.

Der Verfasser. 